\title{
How Evolutionary is Evolutionary Economics?
}

\author{
Christophe Heintz $\cdot$ Werner Callebaut • \\ Luigi Marengo
}

Published online: 22 January 2013

(C) Konrad Lorenz Institute for Evolution and Cognition Research 2013

The original drafts of most of the articles collected in this thematic issue were presented at the workshop "Models of Man for Evolutionary Economics," the 22nd Altenberg Workshop in Theoretical Biology organized by Werner Callebaut, Christophe Heintz, and Luigi Marengo at the Konrad Lorenz Institute for Evolution and Cognition Research (KLI) in Altenberg, Austria in September 2009. The organizers want to express their warm thanks to the KLI Board for their financial support, and to KLI secretary Eva Karner for her most efficient and friendly handling of the workshop logistics.

Richard Nelson, one of the founders of the now booming field of evolutionary economics, highlights that modern economies are always changing, with much of the energy coming from continuing innovation enabled and constrained by "technological paradigms" and the "creative destruction" (Joseph Schumpeter) innovation engenders. Nelson illustrates that Simonian "bounded rationality" better fits the view of human goal-oriented activity

C. Heintz $(\square)$

Department of Cognitive Science, Central European University,

Budapest, Hungary

e-mail: christophe.heintz@gmail.com

W. Callebaut

Konrad Lorenz Institute for Evolution and Cognition Research, Altenberg, Austria

e-mail: werner.callebaut@kli.ac.at

W. Callebaut

Department of Theoretical Biology, University of Vienna,

Vienna, Austria

L. Marengo

Laboratory of Economics and Management, Scuola Superiore

Sant'Anna, Pisa, Italy

e-mail: luigi.marengo@sssup.it contained in evolutionary economics than the full-blown rationality of Homo oeconomicus dear to the neoclassical paradigm, and calls for more attention on behalf of cognitive scientists to the role shared culture plays in molding human cognition and behavior. Eugene Earnshaw, a philosopher, argues that Nelson and Winter's (1982) evolutionary economics, although departing substantially from evolutionary biology's canon, is a legitimate extension of Darwinism to a novel domain, and that the traditional conception of evolution by natural selection requires revision. Bernard Walliser examines "how game theory went to evolution and how biology later considered learning," exemplifies the hybrid use of models of each type, and proposes a common framework for both types of models. Historian and philosopher of science Jean Gayon, comparing Nelson and Winter's (1982) evolutionary economics with evolutionary game theory à la Walliser, shows that they understand natural selection in different ways, and that Nelson and Winter's theory actually exemplifies "behavioral learning" rather than a Darwinian approach. Geoffrey Hodgson and Thorbjørn Knudsen locate their own position (Hodgson and Knudsen 2010) "some way from the most abstract level" of generalized Darwinism. In a two-part article, Werner Callebaut discusses "generalized Darwinism" from the perspective of a philosopher of biology, and points to developments in contemporary biology that look more promising as sources of inspiration for evolutionary economists.

Bertin Martens argues that the economic exchange of knowledge embodied in goods and services constitutes a transmission channel per se (in addition to genetic, epigenetic, cultural, and environmental transmission channels) that makes efficient use of humans' limited cognitive capacity. Developmental psychologist Katherine Nelson contrasts computational theories in psychology and cognitive 
science generally with more naturalistic and "situated" accounts à la Merlin Donald that are consistent with up-todate insights into children's cognitive development, and should be more relevant to evolutionary economics. Ulrich Witt, another evolutionary economics luminary, compares evolutionary and behavioral perspectives on economic behavior, and discusses how preferences relate to the human genetic endowment, and what conclusions are to be drawn from extending the economist's agenda to the analysis of motivations. Nigel Nicholson regrets evolutionary theory's silence on the "self," although, as he argues, it is an evolved capacity that is essential for coevolutionary processes.

In the final article, historian of biology Naomi Beck critically reflects on Friedrich August von Hayek's theory of cultural evolution aimed at defending the superiority of the market order over rational planning, and compares Hayek's theory of cultural group selection with Darwin's.

\section{References}

Hodgson G, Knudsen T (2010) Darwin's conjecture: the search for general principles of social and economic evolution. University of Chicago Press, Chicago

Nelson RR, Winter SG (1982) An evolutionary theory of economic change. Harvard University Press, Cambridge 